$50 \pm 1 \mathrm{mg}(\mathrm{dl}, \mathrm{p}<0.006)$ by the treatment. The changes of the main parameters are summarised in Table 1.

\begin{tabular}{llll}
\multicolumn{4}{l}{ Abstract THU0036 Table 1} \\
& Before Remicade & After Remicade & Significant p-value \\
\hline TC & $209 \pm 25$ & $205 \pm 36$ & \\
LDL-Chol & $131 \pm 24$ & $118 \pm 43$ & \\
HDL-Chol & $56 \pm 12$ & $50 \pm 13$ & $\mathrm{p}<0.006$ \\
TG & $112 \pm 48$ & $133 \pm 53$ & $\mathrm{p}<0.01$ \\
Lpa & 1.1 & 1.4 & \\
\hline
\end{tabular}

Values of the lipid parameters in our 15 patients.

Conclusion This study shows that elevated TG and decreased HDL levels occur in patients with RA and PsA after Infliximab therapy. We suggest that these changes in lipid metabolism may be a factor responsible for an increased development of vascular pathology.

\section{THU0037 CLASS SPECIFIC RHEUMATOID FACTORS AND INTERLEUKIN-13 IN RHEUMATOID ARTHRITIS}

A Spadaro, T Rinaldi, M Bombardieri, R Scrivo, V Riccieri, E Taccari, G Valesini. Medical Therapy, Rheumatology Unit, University of Rome, "La Sapienza", Rome, Italy

\subsection{6/annrheumdis-2001.834}

Background In rheumatoid arthritis (RA) the production of rheumatoid factor (RF) by B-lymphocytes could depend on the action of different cytokines.

Objectives Aim of this study was to detect interleukin 13 (IL13), a potent modulator of B-cell functions ${ }^{1}$, in sera of RA patients in order to investigate the relationship of this cytokine, with different class specific RFs.

Methods We studied 36 consecutive patients with RA, classified according to Arnett criteria and 20 healthy subjects matched for age and sex. In all patients, we evaluated the main clinical and laboratory parameters including the determination of IgM-RF, IgA-RF, IgG-RF and IL-13 by immunoenzimatic methods.

Results We found detectable levels of IL-13 $(>1.56 \mathrm{pg} / \mathrm{ml})$ in $86.1 \%$ of RA patients and in $40 \%$ of controls $(\mathrm{p}<0.0006)$. The IL-13 serum levels were significantly ( $<<0.00001)$ higher in patients with RA (mean/lower and upper 95\% CI $=165.4 / 99.3-$ $231.6 \mathrm{pg} / \mathrm{ml}$ ) respect to the controls (mean/lower and upper $95 \%$ CI $=3.9 / 0.8-7.0 \mathrm{pg} / \mathrm{ml})$. The serum levels of IL-13 correlated with those of IgM-RF $(r=0.591 ; \mathrm{p}<0.0001)$ and IgA$\mathrm{RF}(\mathrm{r}=0.505 ; \mathrm{p}<0.002)$, while we didn't find any relationship with IgG-RF, IgM, IgA and IgG levels. IgA-RF levels correlated with those of $\operatorname{IgM}-\mathrm{RF}(\mathrm{r}=0.548 ; \mathrm{p}<0.0005)$ and IgGRF $(r=0.543 ; p<0.0006)$, while no relationship between IgM-RF and IgG-RF ( $\mathrm{r}=0.222$; n.s.) was found. The comparison of patients with or without the different class specific RFs revealed that patients with IgM-RF had significantly $(\mathrm{p}<0.018)$ higher levels of IL-13 respect to the patients without (mean/ lower and upper 95\% CI $=202.4 / 125.8-278.9$ vs $12.6 / 2.2-$ $22.9 \mathrm{pg} / \mathrm{ml}$ ), while this finding was not observed for IgA-RF (mean/lower and upper 95\% CI $=191.1 / 114.3-267.9$ vs 59.3/58.6-177.2 $\mathrm{pg} / \mathrm{ml}$ ) and IgG-RF(mean/lower and upper 95\% CI $=239.4 / 48.6-430.2$ vs $147.6 / 74.5-220.7 \mathrm{pg} / \mathrm{ml})$. We didn't find any relationship of serum IL-13 levels with clinical and other laboratory signs of disease activity.
Conclusion In conclusion our results show that IL-13 is involved in pathogenetic mechanism of RA, suggesting that IL-13 source could derive from an excessive joint or intravascular production by immune system. A relevant action of IL-13 seems to be related with a selective isotype production of IgM-RF.

\section{REFERENCE}

1 Punnonen J, Aversa G, Cocks BG, McKenzie ANJ, Menon S, Zurawski G, De Waal Malefty R, De Vries JE. Interleukin 13 induces interleukin-4-indipendent IgG4 and IgE synthesis and CD23 expression by human B cells. Proc Natl Acad Sci USA 1993;90:3730-4

\section{THU0038 CYTOKINE AND GROWTH FACTOR REGULATION OF RA AND OA SYNOVIAL MACROPHAGE DIFFERENTIATION INTO OSTEOCLASTS AND DENDRITIC CELLS}

L Danks, NA Athanasou. Nuffield Department of Orthopaedic Surgery, University of Oxford, Oxford, UK

10.1136/annrheumdis-2001.835

Background Rheumatoid arthritis (RA) is a chronic autoimmune inflammatory disease in which an unknown autoantigen is presented to T cells. In RA synovial tissue, fully differentiated dendritic cells (DC) are found in close association with T cells. DC are thought to be the major antigen presenting cells in RA. It has previously been shown that human monocytes differentiate into DC when stimulated with GM-CSF and IL-4 with terminal differentiation promoted by TNFa. We have shown that circulating monocytes and synovial macrophages are stimulated to differentiate into functional osteoclasts in the presence of RANKL, MCSF and dexamethasone (Dex).

Objectives We aimed to determine whether synovial macrophages preferentially differentiate into DC or functional osteoclasts in the presence of specific combinations of cytokines/ growth factors which are known to be involved in the pathogenesis of RA and other inflammatory bone conditions.

Methods Synovial macrophages were isolated from the knee and hip of RA and OA patients. The cells were seeded onto dentine slices and coverslips and cultured for 1, 7 and 14 days in the presence/absence of different combinations of the following factors: RANKL (30 ng/ml), Dex (10-8M), MCSF (0-50 ng/ml), GM-CSF (0-50 ng/ml), IL-4 (10 ng/ml), TNFa (10 ng/ml). Macrophage-osteoclast differentiation was quantified by counting the number of multinucleated, tartrate-resistant acid phosphatase (TRAP) cells present, and by measuring their ability to carry out lacunar resorption on dentine slices. Mature DC were identified by the expression of the marker CD83.

Results In the presence of RANKL, M-CSF and Dex, RA and OA synovial macrophages were maximally stimulated to form osteoclasts; a few cells in these cultures were CD83 positive. The majority were TRAP positive and capable of forming resorption pits on dentine. GM-CSF, IL-4 and TNFa stimulated maximum expression of the mature DC marker CD83 in the cultures; these cultures were TRAP negative and incapable of resorbing dentine. Synovial macrophages cultured in the presence of RANKL and GM-CSF alone resulted in the formation of large multinucleated cells which expressed the marker CD83; a few of these large multinucleated cells were also TRAP positive. Cell cultures treated with GM-CSF were capable of significantly less dentine resorption than cultures treated with RANKL and M-CSF. The addition of RANKL did not modify CD83 expression in any of the above cytokine/growth factor combinations. 
The presence of Dex significantly inhibited the expression of this DC marker in all cultures.

Conclusion This study demonstrates that synovial tissue macrophages have the capacity to differentiate into either functional osteoclasts or mature dendritic cells depending on the presence or absence of specific humoral factors.

\section{REFERENCES}

1 Peters $J H$, Gieseler $R$, Thiele B, Steinbach $F$. Dendritic cells: from ontogenetic orphans to myelomonocytic decendants. Immunol Today 1996;17(6):273-8

2 Highton J, Kean A, Hessian PA, Thomson J, Rietveld J, Hart D. Cells expressing dendritic cell markers are present in the rheumatoid nodule. I Rheumatol. 2000;27(2):339-46

3 Thomas R, MacDonald KP, Petit AR, Cavanagh LL, Padmanabha J, Zehntner S. Dendritic cells and the pathogenesis of rheumatoid arthritis. I Leukoc Biol. 1999;66(2):286-92

\section{THU0039 LOCAL IL-17 GENE THERAPY ACCELERATES COLLAGEN ARTHRITIS WITH SEVERE BONE EROSION AND RANK LIGAND AND RANK EXPRESSION IN SYNOVIAL INFILTRATE AND AT BONE EROSION SITES}

${ }^{1} E$ Lubberts, ${ }^{1} \mathrm{~L}$ Joosten, ${ }^{2} \mathrm{P}$ Schwarzenberger, ${ }^{1} \mathrm{~B}$ Oppers, ${ }^{1} \mathrm{~L}$ Van den Bersselaar, ${ }^{2} \mathrm{JK}$ Kolls, ${ }^{1}$ WB Van den Berg. 'Rheumatology Research Lab., University Medical Center St Radboud, Nijmegen, The Netherlands; ${ }^{2}$ Gene Therapy Program, Louisiana State University, New Orleans, USA

\subsection{6/annrheumdis-2001.836}

\section{Background}

Objectives To examine the effects of local IL-17 application in the knee joint of type II collagen immunised mice on the induction of bone erosion.

Methods Collagen induced arthritis (CIA) was induced in male DBA-1 mice by immunising intradermally at the base of the tail with suboptimal dose of bovine type II collagen. On day 21, mice were given a booster injection (i.p.) of the same dose of type II dissolved in PBS. Just before expected onset, mice were intraarticularly (i.a.) injected into the right knee joint with $10^{\wedge} 7$ pfu of either an IL-17 expressing (AdIL-17) or control (AdControl) recombinant human type 5 adenovirus vector. Five days after the i.a. injection of the viral vector, arthritis was monitored visually and joint pathology was examined by histology. Formation of osteoclast-like cells was determined by tartrate-resistant acid phosphatase (TRAP) staining. In addition, RANKL and RANK protein expression was evaluated by specific immunohistochemistry.

Results Local IL-17 over-expression in the knee joint of type II collagen immunised mice promotes synovial inflammation. Five days after viral injection of AdIL-17, histologic analysis showed aggravation of bone erosion in the patella and femur/tibia region compared with the control vector group. Induction of bone destruction by IL-17 was accompanied with marked TRAP activity in the bone marrow and at bone erosion sites, indicating that IL-17 accelerates the formation of osteoclast-like cells. Interestingly, local IL-17 promotes local protein expression of RANKL and its receptor RANK in the synovial infiltrate and at bone erosion sites compared with the control vector group.

Conclusion These data shows that local IL-17 gene therapy during onset of collagen arthritis promotes osteoclastic bone erosion accompanied with accelerated expression of local RANKL and its receptor RANK. These findings suggest IL-17 to be a potent stimulator of osteoclastogenesis during arthritis.
THU0040 ANAEMIA OF CHRONIC DISEASE (ACD) IN A RODENT MODEL IS SIMILAR TO HUMAN ACD AND CAN BE ALLEVIATED BY ARANESP TREATMENT

K Cooke, G Stoney, W Sutherland, J Pistillo, J Del Castillo, G Molineux, M Coccia. Pathology/Pharmacology, Amgen Inc., Thousand Oaks, USA

\subsection{6/annrheumdis-2001.837}

Background We previously reported that ARANESP ${ }^{\mathrm{TM}}$ alleviates ACD in a rodent model of peptidoglycan-polysaccharide polymer (PG-APS) mediated inflammation. We report here the further characterisation of this model and the effects of ARANESP $^{\mathrm{TM}}$ treatment on ACD.

\section{Objectives}

Methods Immunisation of Lewis rats with PG-APS induces chronic systemic inflammation characterised by relapsing arthritis and hepatic granulomas. Associated with the inflammation is acute, severe anaemia followed by chronic, moderately severe anaemia. As previously established, a $30 \mu \mathrm{g} / \mathrm{kg}$ dose of ARANESP $^{\mathrm{TM}}$ every 2 weeks starting day 36 normalised peripheral blood (PB) haemoglobin levels by day 64 .

Results Acutely anaemic rats had greatly enhanced mean PB reticulocyte counts and greatly reduced mean RBC counts. Mean $\mathrm{PB}$ reticulocyte and $\mathrm{RBC}$ counts normalised during chronic anaemia, but RBC remained hypochromic and microcytic. Individual anaemic rats had transient increases in serum erythropoietin (EPO) concentrations. However, there was no significant difference in mean EPO concentrations compared to controls, which suggests EPO production was blunted. Histology of day 36 and day 112 anaemic rat spleen sections revealed greatly enhanced iron retention by splenic macrophages. In contrast, bone marrow (BM) macrophages were nearly devoid of iron. Serum iron concentratioans were significantly reduced by day 7 and remained low throughout the study. Interestingly, ARANESP ${ }^{\mathrm{TM}}$ treated rats showed decreased iron retention in macrophages and increased serum iron starting day 98. To identify which cytokines may contribute to the chronic anaemia of this model, peritoneal exudate cells (PEC) were isolated and challenged with PG-APS in vitro. Unstimulated PEC produced little or no cytokines. PG-APS challenged PEC from anaemic rats produced IL- $1 \alpha$, TNF- $\alpha$, and IFN- $\gamma$. PG-APS challenged PEC from ARANESP ${ }^{\mathrm{TM}}$ treated anaemic rats trended towards reduced levels of these cytokines relative to anaemic PEC cultures.

Conclusion In summary, we have shown this ACD model is similar to human ACD. Importantly, ARANESP ${ }^{\mathrm{TM}}$ treatment alleviates ACD in this model, thus indicating its potential therapeutic utility for human ACD.

\section{THU0041 DISTINCT EFFECTS OF TNFALPHA BLOCKADE FROM TNFALPHA AND LTALPHA BLOCKADE IN A PRIMATE MODEL OF SUBCUTANEOUS ABSCESS FORMATION}

XR Song, F Fox, MA Gallo, A Rosenberg, R Jordan, C Wagner. $R$ \& D, Centocor, Malvern, USA

\subsection{6/annrheumdis-2001.838}

Background TNF $\alpha$ exerts both physiologic and pathologic effects in response to infection conferring the benefit of host defense against infection at the risk of eliciting severe pathology if the response is excessive or inappropriate.

Objectives To examine whether the currently used anti-TNF therapy would affect the innate response to infections in an animal model of subcutaneous abscess formation. 